\title{
Design of Intelligent System for Watering Flowers Based on IOT
}

\author{
Hong-Jun GUª , Shi-Dong Zhu, Yan-Fen YANG, Li-Xin YANG, Ai-Ying LI, \\ Qi-Zhi LIU and Shi-Jun LI ${ }^{\text {b, }}$ \\ Jilin Agricultural University, Changchun 130118, Jilin, China \\ aghj_dennis@163.com, 'PIsj0883@sina.com \\ *Shi-Jun LI
}

Keywords: watering device, IOT, ZigBee, remote control.

\begin{abstract}
This paper designs a new intelligent system for watering flowers based on internet of things (IOT), which is suitable for indoor, balcony and courtyard, etc. When the flowers are neglected in long-term, intelligent device for watering flowers can do the watering operation timely and quantitatively. This device is composed of a master node and several slave nodes which communicate via ZigBee modules. A smartphone or a remote controller can control this device at any time.
\end{abstract}

\section{Introduction}

In recent years, people have been paying increasing attention to their living environment quality with the rise of living standard. Raising flowers, which can beautify the environment, purify the air, cultivate the human spirit and maintain the physical and mental health of people, has become a favorite household ornament.

Many people in cities, facing the fast pace of life and the big social pressure, need to deal with many and complex things, so they often forget watering their flowers[1]. The flowers without water in long-term will wither or die. Some flowers have a high requirement for the soil moisture. Excess water can result in the rot of the flower roots. To solve the actual problem, an intelligent watering system is designed based on IOT[2]. IOT is an important part of the new generation information technology, and is also the important stage of information age development, which has been widely used in many fields[3].

Some developed countries have already begun to popularize the related systems or devices with reliable performances and powerful function. However, the price is much higher than the flowers, so the systems are not suitable for the families in developing countries.

Watering devices on the market in China can not water the flowers timely and quantitatively or realize the remote alarm functions. Today, IOT technology has developed rapidly, and has many advantages of low price, high stability and wide application, which can be used in the intelligent watering system $[4,5]$. This system includes a watering device and a smartphone.

\section{Design of the Hardware Circuits}

This device is composed of a master node and several slave nodes (the number of slave nodes depends on the users' needs). The master node uses ZigBee module as the core, supplemented by the keyboard circuit, display circuit, clock module, moisture sensor, control switch, remote controller, GSM module, and antenna, etc. The slave nodes, consisting of the ZigBee module, antenna, moisture sensor, control switch and pump, are simpler than the master node, which is considered of the low costs and actual needs. The structure diagram of the master node is shown in Fig. 1 and that of the slave node need not repeat here. Remote controller adopts the common infrared remote controller[6].

The keyboard circuit can adjust the dates, the times and the time intervals for watering, and adjust the current displaying times by clock chip DS1302. The moisture sensor adopts self-developed resistance strain sensor for lowering the costs. The on-off states of the control switch are controlled by ZigBee. Remote controller and smartphone can realize the watering action by wireless transmission. The antenna can transmit the related information between nodes. The GSM module can 
communicate between the master node and the smartphone. The display screen can shows some useful information, such as, the current date and time, watering time intervals, soil moisture data and the control switch states and so on. Several important modules and circuits are given in the following.

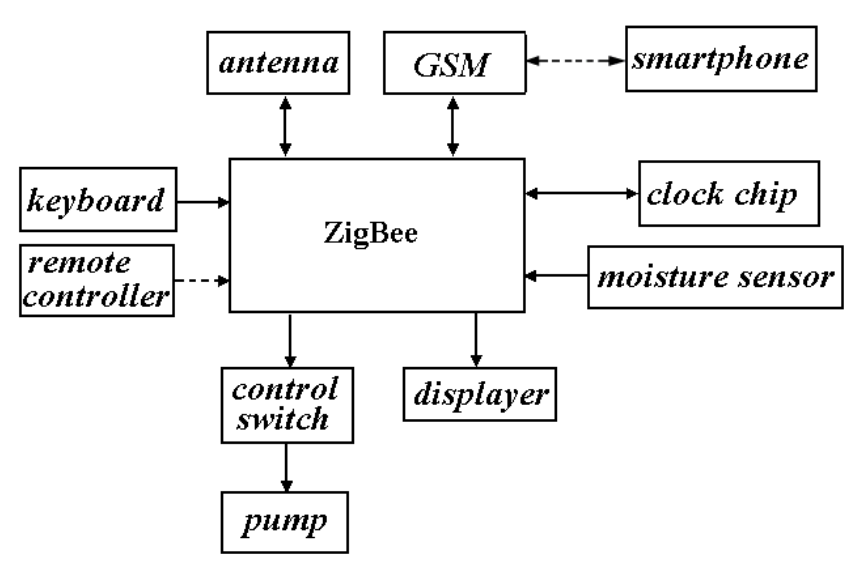

Fig. 1 The system structure diagram of the master node

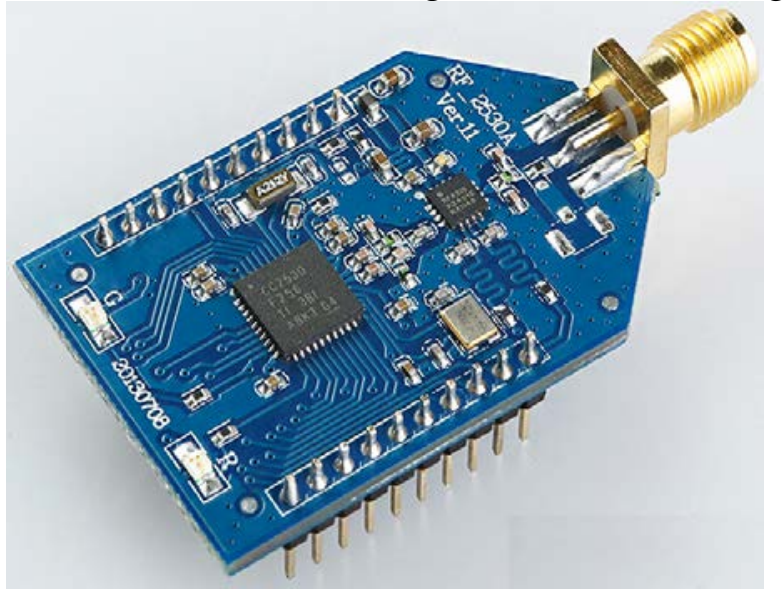

Fig. 2 The ZigBee physical model

As shown in Fig. 2, ZigBee (the core is CC2530), typically used in IOT, is the control core of this watering device. CC2530 has many advantages: very low power, low price, high reliability, self-organized network, low delay and wide application, and it integrates Single Chip Microcomputer, ADC and wireless communication module. CC2530 can communicate with the circuits and modules around it, and it can realize its strong functions.

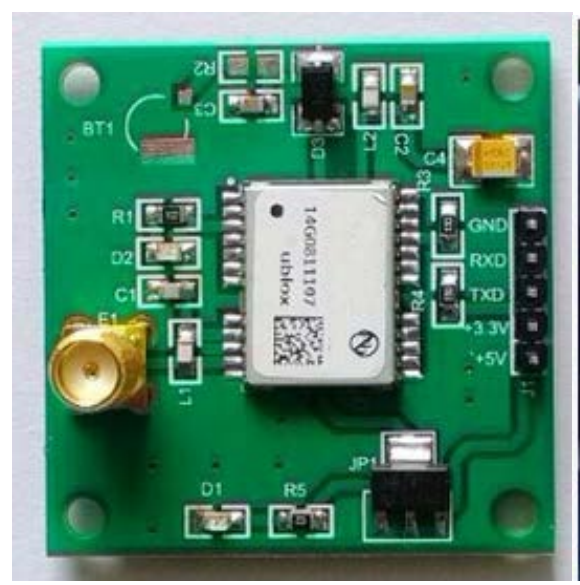

Fig. 3 The GSM physical model

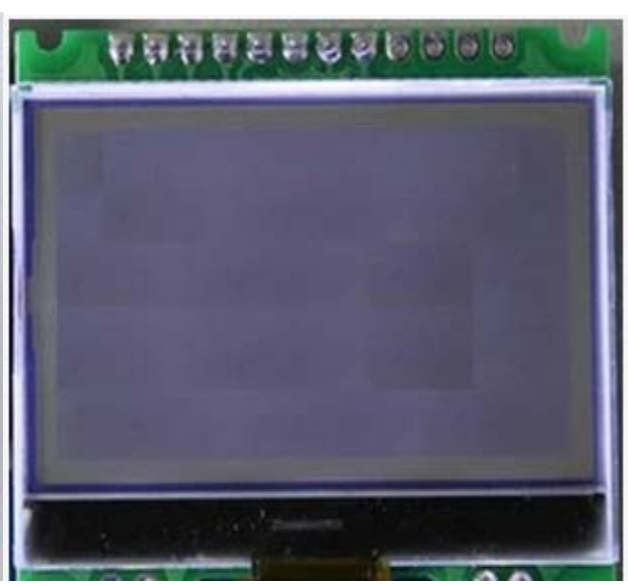

Fig. 4 The display screen physical model

GSM physical model is shown in Fig. 3. It has five pins: GND, RXD, TXD, POWER 3.3V and 5V, so it communicate with ZigBee via serial ports. The power adopts 3.3V which is the same as ZigBee.

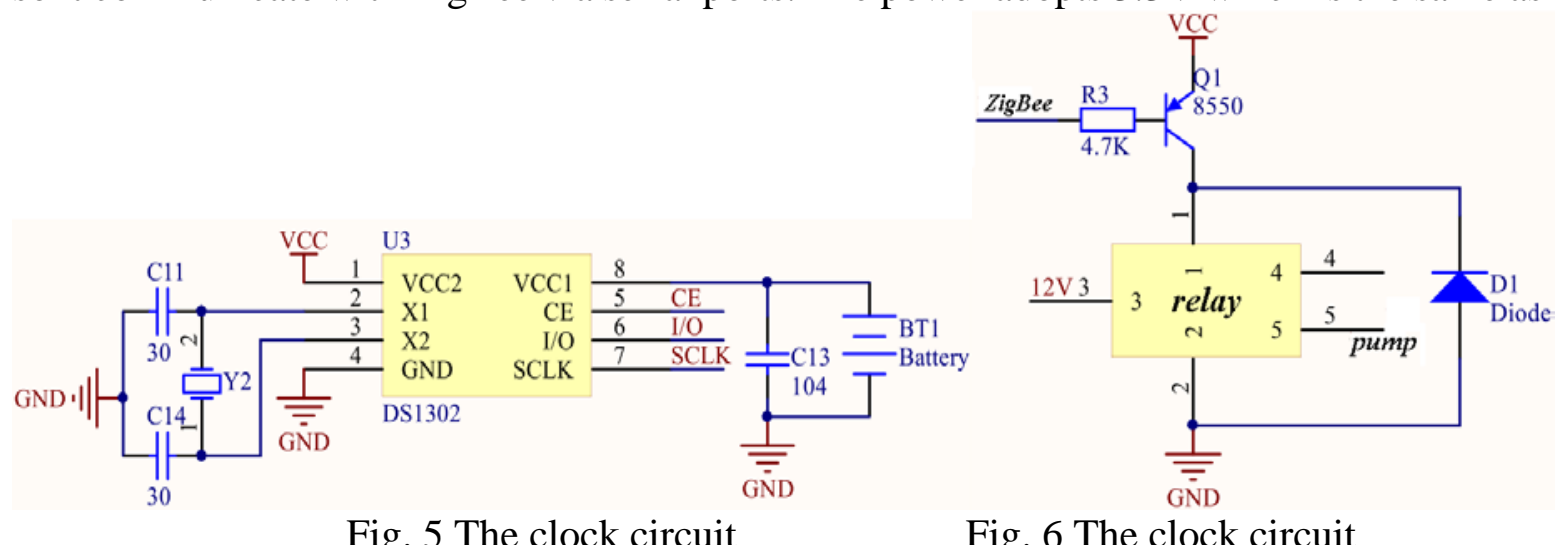

Fig. 5 The clock circuit

Fig. 6 The clock circuit 


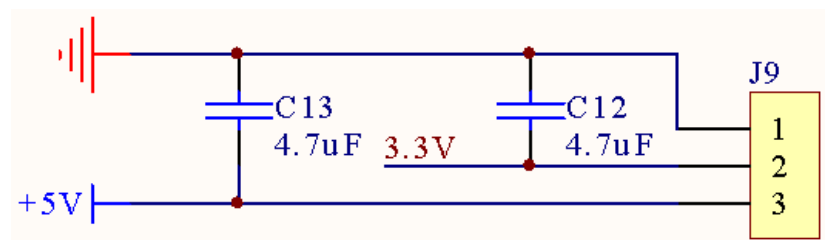

Fig. 7 The clock circuit

As shown in Fig. 4, the display screen LCD12864 has SPI bus connecting directly ZigBee. ZigBee writes some data into the LCD12864. The display screen can show the current date and time, soil moisture, the work states of pumps. The users can set and inquire the date, time and time interval for watering from the display screen via keyboard.

As shown in Fig. 5, the clock circuit adopts DS1320, its pin VCC2 connects the system power, pin VCC1 connects reserve power supply, pin X1 and X2 connect the crystal oscillator with $32.768 \mathrm{KHz}$, and pin CE, I/O and SCLK connects ZigBee. ZigBee can read out and write in the dates and times via the chip DS1320.

Control switch circuit is shown in Fig. 6. ZigBee chip controls the transistor to drive the relay. When ZigBee chip pin outputs ' 0 ' level, the watering job starts. When ZigBee chip pin outputs ' 1 ' level, the watering job ends.

As shown in Fig. 7, the voltage regulator IC, ASM1117, can convert 5V input voltage into 3.3V output voltage for ZigBee and GSM modules.

\section{Design of the Software Flows}
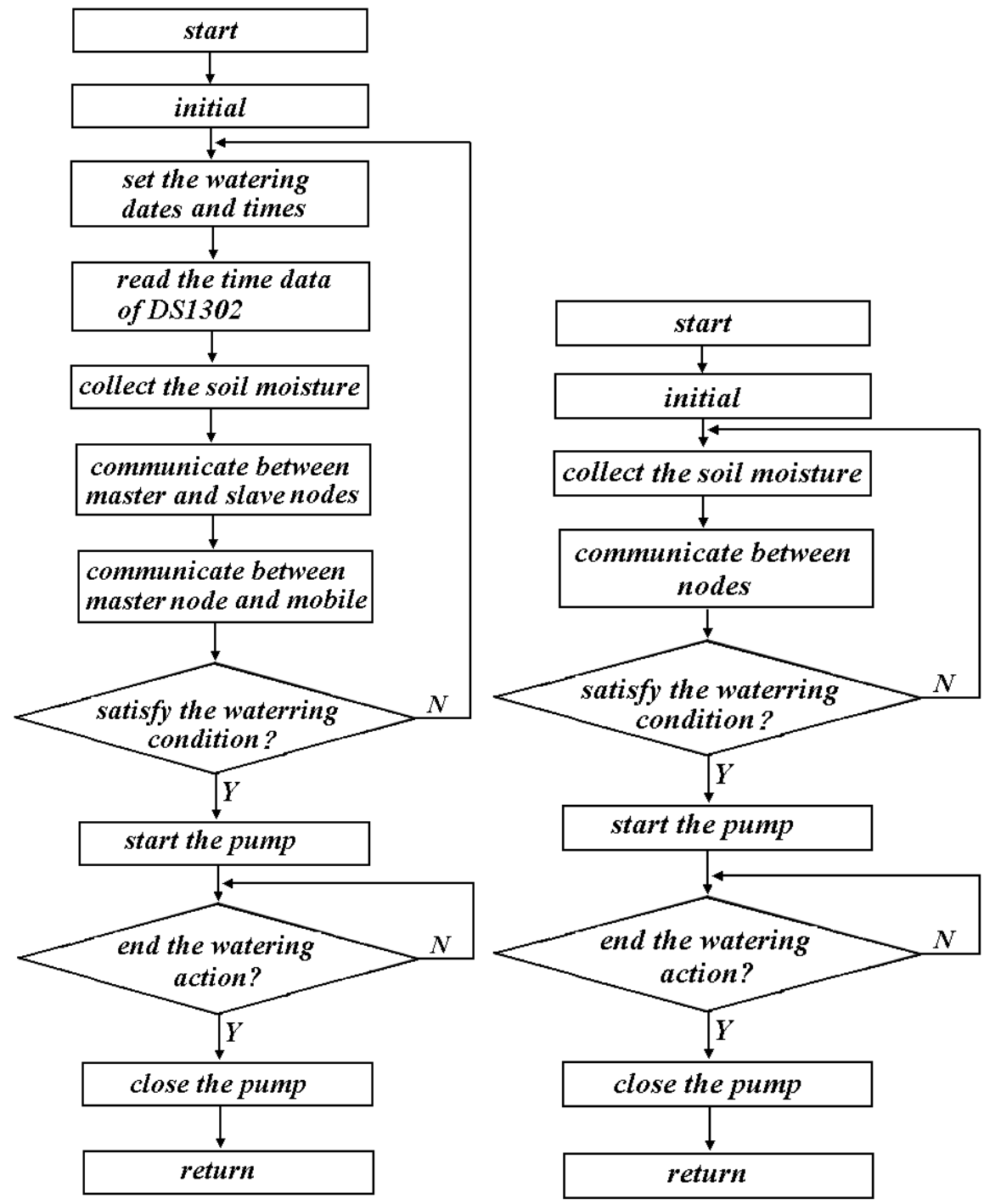

Fig. 8 The master node flow diagram

Fig. 9 The slave node flow diagram 


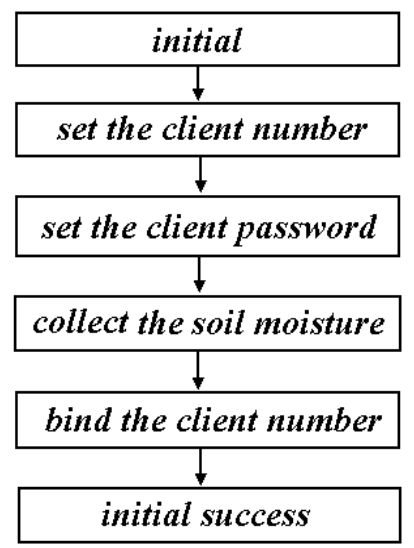

Fig. 10 The smartphone register flow diagram

Fig. 8 shows the master node flow diagram. First, CC2530 initializes itself, GSM, clock chip and display screen and so on, then sets the watering dates, times and time intervals for watering, of course, it can also set the current date and time. Next, CC2530 collects the soil moisture, communicates with the nearest slave node from it. Last, CC2530 judges whether watering action gets satisfied, start the pump to water flowers if the condition is met. And CC2530 judges whether watering action should be finished, if the condition is satisfied, the pump is closed and end watering.

Fig. 9 shows the slave node flow diagram. CC2530 does the initialization, collects the soil moisture, communicates with the near slave nodes. The following process is the same as the master node flow diagram.

Fig. 10 shows the smartphone register flow diagram, the first step is to enter initial operation after smartphone software is installed, then set the client number (in the SIM card), and bind it. So the initial process succeeds, and the user can use the smartphone to communicate with the GSM module. The only registered user can use his smartphone to control the device to water flowers.

\section{Conclusions}

This paper designs a new intelligent system for watering flowers based on IOT. This system solves the issue that the flowers wither without watering timely or the roots are rotted with excess water. In order to test the performance of this system, master node is put in the balcony, other three slave nodes are put in the windowsill of three bedrooms, respectively. The watering device can do the watering action timely and quantitatively. Remote controller and smartphone can control the device to water the flowers at any time. Experiments show that this system works stably and can be expanded to agricultural greenhouses after a few of modifications. So this system has broad prospects in application.

\section{Acknowledgments}

The corresponding author, Shi-Jun LI, and other authors wish to express their gratitude to the projects, Jilin Province University Students' Innovation and Entrepreneurship Project, Jilin Province Economic Structural Adjustment Leading Fund Special Project (No. 2014Y108) and Changchun City Science and Technology Plan Project (No. 14nk029), Jilin Agricultural University, for their generous support of this work.

\section{References}

[1] Deyang Wang: Journal of Sichuan Ordnance. Vol. 34(2013) p.113-115, in Chinese. 
[2] Qingquan Cui, Xunhe Yin: Electronic Measurement Technology. Vol. 38(2015) p.109-112, in Chinese.

[3] Zhaopeng Zhang: Electronic Design Engineering. Vol. 19(2011) p.39- 42, in Chinese.

[4] Li Zhao, Chunlin Zhang: Journal of Changchun University. Vol. 22(2012) p.650-652, in Chinese.

[5] Liang Xiong, Aiping Zhu: Ningxia Engineering Technology. Vol. 12(2013) p.18-19, in Chinese.

[6] Yumin Lu, Limin Mao, Jiajuan Qin, et al: Journal of Changshu Institute Technology. Vol. 27(2013) p.104-108, in Chinese. 